\title{
CAECAL PERFORATION SECONDARY TO IDIOPATHIC CAECAL DILATATION- AN INTERESTING CASE
}

Haripriya Reddy, Karigalan. K.

1. Assistant Professor, M.S. Department of General Surgery, P.E.S.I.M.S.R, Kuppam. Andhra Pradesh.

2. Assistant Professor, M.S. Department of General Surgery, P.E.S.I.M.S.R, Kuppam. Andhra Pradesh.

\section{CORRESPONDING AUTHOR}

Dr. Haripriya Reddy

No. 202, second floor, Staff quarters,

P.E.S.I.M.S.R, Kuppam, A.P

E-mail: haari_priyaa@yahoo.com,

Ph: 00919700765933

ABSTRACT:Acute pseudo-obstruction of the colon(Ogilvie's syndrome) involves acute colonic distension without mechanical obstruction or stercoroma in a previously healthy colon. Colonic pseudo-obstruction can be diffuse or segmental. The cause for idiopathic colon dilatation is not known. Caecal rupture due to colonic ileus is rare and has a mortality rate of 43 per cent. We report a case of idiopathic caecal dilatation causing caecal perforation. On emergency laparotomy, caecal perforation secondary to segmental caecal dilatation without organic obstruction was found in this patient.

KEYWORDS: Acute pseudo-obstruction of the colon; Idiopathic caecal dilatation; Caecal perforation; Emergency laparotomy

MESH TERMS: Colonic Pseudo-Obstruction; Intestinal Pseudo-Obstruction, Idiopathic; Intestinal Perforation; Laparotomy

INTRODUCTION: Colonic pseudo-obstruction is a type of adynamic ileus. It can be "idiopathic" or can complicate other diseases or surgical procedures (urological and gynaecological procedures mostly). Conservative treatment is the method of choice but when the caecal diameter is more than $12 \mathrm{~cm}$ (impending perforation), when the colon is perforated or when medical measures are unsuccessful, surgical procedure is compulsory. Even with a proper management, the prognosis is severe and the mortality rate is high (3-50\%).

We report this case of idiopathic caecal dilatation causing caecal perforation as it can be often misdiagnosed and has a high mortality rate. Hence, always consider colonic pseudo-obstruction as a differential diagnosis for any case of subacute or acute large bowel obstruction.

CASE REPORT: A 25 year old female patient was admitted with abdominal pain, abdominal distension, fever and vomiting of 3 days duration. Patient was never admitted for any complaints in the past nor has undergone any abdominal surgeries.

General examination revealed a pulse rate of $72 / \mathrm{min}$, blood pressure of $120 / 80 \mathrm{mmh}$ with normal temperature. On systemic examination, abdomen was soft and distended, shifting dullness was present. No guarding or rigidity. Bowel sounds were sluggish. All blood investigations were within normal limits. Erect $x$ ray abdomen showed dilated large bowel loops with few air fluid levels but no air under diaphragm (Fig.1). Ultrasound abdomen showed features of subacute intestinal obstruction with ascites. 
Patient was put on conservative treatment. She improved symptomatically but the symptoms recurred after a period of 10 days. Clinically, patient became sick with a palpable mass in the right iliac fossa. CECT abdomen revealed grossly dilated caecum and multiple loculated collections in pelvis with thickened omentum and peritoneum (Fig.2).

Patient underwent emergency laparotomy. Grossly dilated caecum of $>10 \mathrm{~cm}$ diameter with $0.5 \times 0.5 \mathrm{~cm}$ caecal perforation was noted (Fig. 3 ). Caecum was not mobile. No obstruction in the distal colon noted. Appendix was normal and found adhered to the caecum retrocaecally. Omental and peritoneal thickening with pelvic exudates were noted.

First caecum was decompressed. Then, Right hemicolectomy with side to side ileotransverse anastomosis was done. Peritoneal lavage done and bilateral pelvic drains placed. Patient was given total parenteral nutrition for 1 week and her general condition was improved. Patient postop recovery was uneventful and was discharged on postop day 14 . Histopathological examination of the specimen revealed no obvious pathology responsible for the segmental large bowel dilatation and caecal perforation.

DISCUSSION: Pseudoobstruction of the colon is a specific variety of adynamic ileus. The clinical and radiologic picture closely resembles mechanical obstruction of the large bowel (1).

The pathophysiology of the syndrome is still unknown. Ogilvie, who first described the syndrome in 1948, suggested an imbalance between the sympathetic and parasympathetic innervation of the colon (2).

The most relevant clinical finding in Ogilvie's syndrome is abdominal distension, which arises suddenly, has a progressive course and reaches massive levels. The first-line diagnostic investigation is plain abdominal radiography which shows extreme colon dilation without airfluid levels of the small intestine (3).

The bowel distension in colonic pseudo-obstruction is from swallowed air so stop oral intake and decompress the stomach with nasogastric tube. Goal is to prevent colonic perforation as acute pseudo-obstruction of colon is self-limiting (4). Caecal rupture due to colonic ileus is rare and has a mortality rate of 43 per cent. The disease has always occurred in association with another illness, has usually afflicted patients over the age of 55 and has only resulted when the caecum was at least $9 \mathrm{~cm}$ in diameter (5).

The acute colonic pseudo-obstruction, Ogilvie's Syndrome, most often appears as a complication of other clinical conditions like restrictive respiratory dysfunction (6). Principal associated diseases are cardiopulmonary insufficiencies, postoperative conditions, and systemic disorders (7).

There are many other conditions that mimic colonic pseudo-obstruction which are vascular lesions of gut, lead poisoning, porphyria, acute pancreatitis, acute cholecystitis, acute appendicitis, acute dysentery and morphine overdosage (8).

Pseudo-obstruction of the colon is a potentially lethal condition. The diagnosis should be suspected in a patient with derangement of a major extra-abdominal organ system in whom abdominal distension develops (9). The most severe complication is cecal rupture, which may occur at a diameter of $12 \mathrm{~cm}$ or more and which has a lethality rate of $40 \%$ (10).

In 1978, authors reported a new case of caecal perforation complicating acute dilatation of the colon without organic obstruction (Ogilvie's syndrome). They recall the two characteristics of this syndrome : abdominal distension due to colonic ileus, without any organic cause, and the constant coexistence of an associated pathological condition (traumatic, post-

Journal of Evolution of Medical and Dental Sciences/Volume1/Issue5/November-2012Page-889 
operative, infective, cardio-vascular, respiratory or neurological). The pathogenesis of Ogilvie's syndrome remains mysterious (11).

Diagnosis is generally made on the basis of the plain roentgenogram of the abdomen and a barium enema of the colon (12). Endoscopic decompression and tube placement is effective and safe for acute colonic pseudo-obstruction not responding to 24 hour conservative treatment (13). Surgery should only be envisaged when there are setbacks, due to the seriousness of the operation and the possibility of postoperative complications (14).

In reviewing 750 cases of acute colonic pseudo-obstruction from the literature, the most commonly associated disorders are listed and the therapeutical management is critically discussed. Ogilvie's syndrome has been used synonymously with acute colonic pseudoobstruction (ACPO) of the colon, first defined by Sir Heneage Ogilvie in 1948. If inappropriately managed, the massive colonic dilatation may lead to caecal ischaemia and perforation with a high mortality rate. Conservative treatment is indicated if the caecum is less than $12 \mathrm{~cm}$ in diameter. If there is a progressive increase in diameter or no improvement is seen, the colon should be decompressed without further delay. The indications for surgery are failure of conservative treatment and colonoscopy, signs for ceacal ischaemia or perforation. The choice of procedure, caecostomy or resection, is dictated by the state of the caecum. Due to a high mortality rate (up to $50 \%$ ) if the caecum is perforated, an aggressive therapeutical management should be applied (15).

\section{REFERENCES:}

1. Bachulis BL, Smith PE. Pseudoobstruction of the colon. Am J Surg. 1978 Jul;136(1):66-72. [PubMed]

2. Nanni G, Garbini A, Luchetti P, Nanni G, Ronconi P, Castagneto M. Ogilvie's syndrome (acute colonic pseudo-obstruction): review of the literature (October 1948 to March 1980) and report of four additional cases. Dis Colon Rectum. 1982 Mar; 25(2):157-66. Review. PubMed PMID: 7039994.

3. Grassi R, Cappabianca S, Porto A, Sacco M, Montemarano E, Quarantelli M, Di Mizio R, De Rosa R. Ogilvie's syndrome (acute colonic pseudo-obstruction): review of the literature and report of 6 additional cases. Radiol Med. 2005 Apr; 109(4):370-5. Review. English, Italian. PubMed PMID: 15883521.

4. Nivatvongs S, Vermeulen FD, Fang DT. Colonoscopic decompression of acute pseudoobstruction of the colon. Ann Surg. 1982 Nov;196(5):598-600. [PMC free article] [PubMed]

5. Gierson ED, Storm FK, Shaw W, Coyne SK. Caecal rupture due to colonic ileus. Br J Surg. 1975 May;62(5):383-386. [PubMed]

6. Georgescu S, Dubei L, Zaharia M, Cîrdei C, Crumpei F, Cijevschi-Prelipcean C, Stoian M. Ogilvie's syndrome--acute colonic pseudo-obstruction. Case report and review of the literature. Rom J Gastroenterol. 2003 Mar;12(1):51-5. Review. PubMed PMID: 12673381.

7. Wegener M, Börsch G. Acute colonic pseudo-obstruction (Ogilvie's syndrome).Presentation of 14 of our own cases and analysis of 1027 cases reported in the literature. Surg Endosc. 1987;1(3):169-74. Review. PubMed PMID: 3332478.

8. Stephens FO. Syndrome of Intestinal Pseudo-obstruction. Br Med J. 1962 May 5;1(5287):1248-1238.2. [PMC free article] [PubMed]

9. Melzig EP, Terz JJ. Pseudo-obstruction of the colon. Arch Surg. 1978 Oct;113(10):11861190. [PubMed]

Journal of Evolution of Medical and Dental Sciences/Volume1/Issue5/November-2012Page-890 
10. Ritschard T, Filippini L. [Acute pseudo-obstruction of the colon (Ogilvie's syndrome). Internal medicine aspects]. Schweiz Med Wochenschr. 1985 May 4;115(18):614-9. German. PubMed PMID: 3839093.

11. Leborgne J, Pannier M, Le Neel JC. [Cecum perforation, complication of an acute idiopathic dilatation of the colon, or Ogilvie's syndrome. Practical interest of various pathogenic data. Apropos of one case]. Sem Hop. 1978 Jun;54(17-20):665-8. French. PubMed PMID: 211619.

12. Schippers E, Raguse T, Brenner P, Dyballa G. [Pseudo-obstruction of the colon]. Zentralbl Chir. 1983;108(20):1249-62. Review. German. PubMed PMID: 6359773.

13. Naef M, Maurer CA, Scheurer U, Seidel K, Langen HP, Sell F, Büchler MW. [Idiopathic dilatation of the large intestine (Ogilvie syndrome-acute pseudo-obstruction)]. Zentralbl Chir. 1998;123(12):1360-4. German. PubMed PMID: 10063545.

14. Pinta P, Offenstadt G, Guidet B, Senouci M. [Syndrome of acute colonic pseudo-obstruction (Ogilvie's syndrome). Study of 13 cases]. Ann Gastroenterol Hepatol (Paris). 1986 MarApr;22(2):69-76. French. PubMed PMID: 3717887

15. Meier C, Di Lazzaro M, Decurtins M. [Ogilvie syndrome with cecal perforation. A rare complication after isolated thoracic trauma. Case report and current literature review]. Swiss Surg. 2000;6(4):184-91. Review. German. PubMed PMID: 10967947.

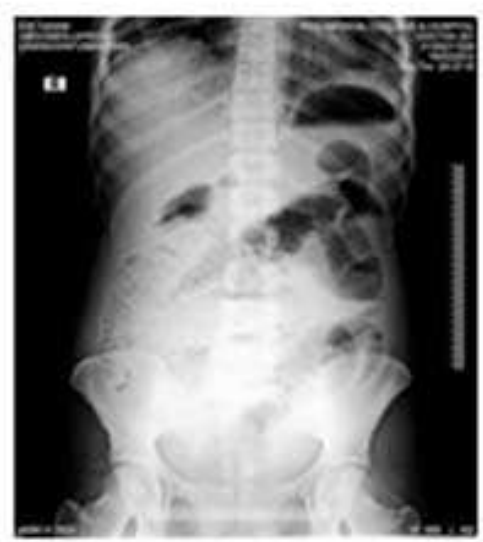

Fig.1 Dilated large bowel loops with distended Caecum and Right colon

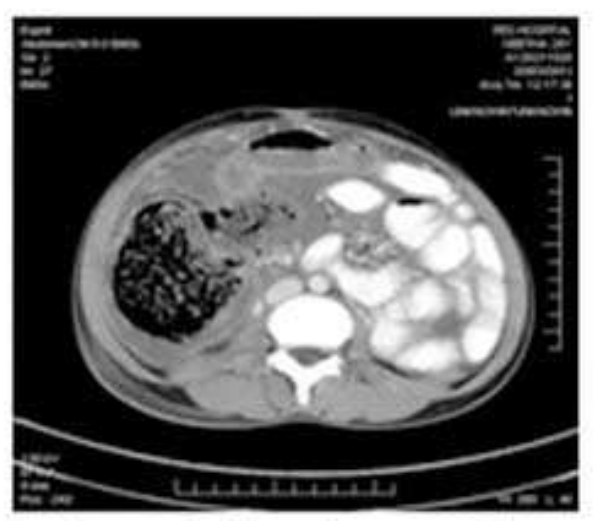

Fig.2 Grossly dilated caecum of $>10 \mathrm{~cm}$ diameter

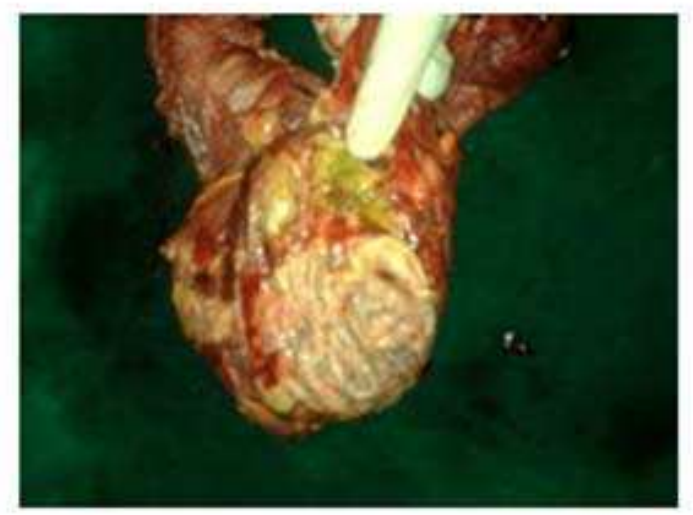

Fig 3 Right hemicolectomy specimen showing decompressed caecum with perforation 